\title{
Opening the Airing Cupboard from All Sides
}

To say in a sentence what this book is about, I would venture that it is: an intention to explore positionality in the postdigital context that Higher Education (HE) now inhabits, to raise open debate on the implications for individuals and for $H E$ inclusivity policies. As such, this preface sets the scene by discussing some assumptions and challenges this book will explore. However, as odd as it may sound, I begin this debate by opening up the airing cupboard...

Airing broad and varied viewpoints to contribute to ideas on inclusivity is not an easy thing to do in our current cultural climate. Some debates can, speaking metaphorically, resemble pulling out the same old sheets from an airing cupboard.

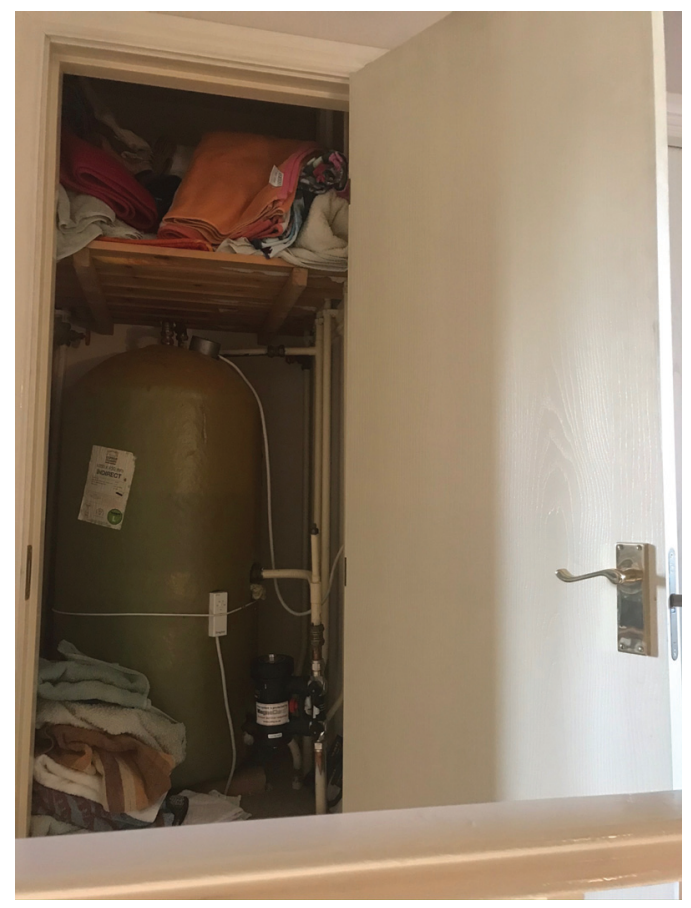

FIGURE 1

Airing cupboard

The arguments that seem to get aired and re-aired are the more popular, recent and easy-to-reach ones, just like the comfortable, well-worn sheets that fall out on you, as you open the airing cupboard door. In a very full airing cupboard, the tank and pipes inside are concealed by all that is happening up 
front. It would be easy to forget that these mechanisms are there in the background, to ensure the warm air continues to circulate. Then there is also a risk that, whilst I am searching towards the back of the cupboard, a discovery of some dirty laundry brings to mind the old adage: how much of this should be aired anyway?

The saying 'don't air your dirty laundry in public' originates from physical situations where dirty laundry (really an analogy for unpleasant or inconvenient secrets) was supposed to remain hidden when visitors called, in case any revelations led to embarrassment for a family. If I place my scruffy linen on a washing line outside though, it will only be noticed by people passing by and perhaps the odd drone circling overhead. If I sit in a room with family and share a few dirty secrets, then these too are only passed between those who are present.

These days though, across virtual news and social media websites on the Internet, personal stories abound alongside expressions of offence taken by others to opinions, values or events described. These are not only tales of an occasion and related reactions and experiences, however. These are also data. This may be data I do not realise has been gathered when I spoke to a news channel, posted a tweet or a photo, interacted with classmates on a data-driven system for my university studies, or taught a class online. Data is collected with all kinds of potential re-use in mind, but unlike scruffy laundry items, data can travel quickly and simultaneously into many other systems. It can cross fluid boundaries that are human, technological, biological, political, economic and linguistic with new, far-reaching implications for human ontologies (Peters, 2019, Peters, Jandrić \& Hayes, 2021a, 2021b). Perhaps in the past the so-called dirty laundry led to families refusing to speak to, or to visit each other. Such snubs can now be achieved with much larger public audiences on online platforms, via the 'virtual airing cupboard' of the Internet. We might think of it as rather like a massive airing cupboard, where the physical 'tank and pipes' (and who and what is powering these) are easily overlooked in the entanglements up front.

\section{Virtual Airing Cupboards}

One way to play with such a metaphor for links between online communications across data-driven systems and issues of inclusivity is to imagine that, rather than opening the door of the physical airing cupboard at the top of your stairs (should your home have any stairs) you are typing into your preferred Internet browser which takes you into the virtual airing cupboard. The sheets 
of information before you, in the form of web pages, are not so unlike the old sheets picked out from the airing cupboard in the hallway, as they fall out from the front. Maybe you consciously saved and bookmarked some searches, or maybe a device you are using decided on your behalf to present you with topics and items you have recently browsed or purchased.

These online activities are evolving into 'onto-platforms' that know us and our 'hourly fluctuations of the self - better than we can know ourselves' (Peters, 2019). Such a situation has ongoing implications too for how each of us finds ourselves positioned as a human being, for our perceptions of personal opportunities, identity and inclusion. For example, it is worth reflecting on just how often some form of verification is expected from each of us in our activities online. As Braidotti points out in Posthuman Knowledge (2019), the process of confirming that you are 'not a robot' has now become a routine aspect of transactions across the Internet. It is much harder to raise questions ourselves of the systems we access such as 'do you plan to sell my data?' or 'what commercial interests and economic partnerships lie behind this system that I am writing my most intimate details into?' The imperative to verify our human identity effects a shift where the central point of reference is now 'the algorithmic culture of computational networks - not the human' (Braidotti, 2019a: 1).

Algorithmic activity of this nature, despite the complex programming behind it, has slipped quietly (and often unnoticed) into the daily activities of many humans. It did not though arrive accidentally. Programmers were trained in universities, companies hired them and the hardware and software we use, and that uses us as data, was designed and distributed. Yet the universities where so much scientific and technological research and innovation originates, are also ideally positioned to lead critical debate on related societal knowledge and new potential to reduce or exacerbate inequalities. What complicates this is that universities, within global political economy, have become closely interlinked with corporate businesses with strong economic interests in the data driven systems and analytics that operate across the virtual airing cupboard of the Internet (Ball, 202O, Ramge, 2020, Williamson, 2019a, 2019b, $2020 \mathrm{a}, 2 \mathrm{O} 2 \mathrm{Ob}, 2 \mathrm{O} 2 \mathrm{Oc}$ ). Universities are therefore entangled in a situation where 'software code, algorithms, data analytics and infrastructures have become inseparable from policy processes and modes of governance' (Williamson, 2019a: 1).

Yet in HE policy, despite the widespread digitalisation of university activities, a coherent and transparent approach towards the implications this has for inclusivity has yet to be demonstrated. Whilst one part of the university is busy generating policy for areas that digital technologies might enhance, not far across the campus, a different set of strategies to address equality, 
diversity, inclusivity, or measure student participation, retention and success are also being churned out for audit and regulation. There is little dialogue (if any) between HE policy for inclusivity concerning people, and university policy relating to cutting edge research and impact across a broad digitalisation of science and efforts towards a circular bioeconomy (OECD, 2020, Aguilar, Twardowski \& Wohlgemuth, 2020). Yet such research now has far reaching implications for shifts in human identity, and indeed in how existence itself, is understood (Peters, Jandrić \& Hayes, 2021a, 2021b).

Postdigital Airing Cupboards

In a postdigital conception of $\mathrm{HE}$, all of these dimensions are perceived to be interconnected. A growing body of literature is offering deeply contextual interpretations of what it means to be 'postdigital' (Pepperell \& Punt, 2000, Cramer, 2015, Jandrić, Knox, Besley, Ryberg, Suoranta \& Hayes, 2018). For some, this entails rejection of an implied conceptual shift of the 'digital revolution', a shift apparently as abrupt as the 'on/off' logic of the machines now pervading people's daily lives (Pepperell \& Punt, 2000: 2). Boellstorff (2016) draws attention to: 'a key sticking point in contemporary theories of technology' that holds direct relevance for this book: 'the false opposition of the digital and the real'. Calling this a fundamental misrepresentation, Boellstorff raises the issue of the language we use when we talk of the physical as 'real' and compare this with terms like 'digital', 'online', or 'virtual', to infer that these are somehow less real. Firstly, such 'conflations of physical with real, and digital with unreal, even in rhetorical passing, have devastating consequences for addressing the reality of the digital'. Secondly, this presumptive gap reflects 'deep-seated assumptions about value, legitimacy, and consequence' (Boellstorff, 2016: 387). This brings concerns for equality and inclusivity, as it 'forecloses comprehensively examining world makings and social constructions of reality in a digital age' (Boellstorff, 2016: 388).

This means that a discussion of the postdigital context we now occupy is a feminist issue too, when it concerns education that is analogue, digital, or postdigital in on/offline worlds (Deepwell, 2020). Pointing to the 'reality of flawed, broken, and partial coverage of subjects, identities, and visibilities online - particularly for women', Deepwell cites a 'failure to record or capture so much of feminist knowledge production or women's experiences of the world'. She contrasts rhetoric surrounding the Internet and its promised capacity for change with the reality of 'overload' and she asks whether feminist knowledge has ever fully had a digital paradigm? A good question, given that a look at 'the systems 
that distribute power and money in the internet era' reveal that 'the winners are overwhelmingly white, overwhelmingly male, and overwhelmingly from the kind of background that was doing pretty much fine before the Internet too' (Ball, 2020: 225). When Deepwell reflects on whether this is 'a problem for a postdigital education or for humanity', I would suggest that we need to interrogate both.

In a postdigital society there are no hard boundaries separating what takes place for individuals across the virtual airing cupboard of the Internet and their arrival to study, teach, research or hold a leadership role in HE. They bring with them a unique positionality, but one that is now subject to much fragmentation due to blurs in what is considered natural or organic, digital, engineered, or synthetic (Peters, Jandrić \& Hayes, 2021a). Whilst in some interpretations a postdigital context could simply mean accepting that digital is now in the background and just part of the fabric of our society, there are reasons to examine digitalisation as fundamentally much more. Even in the process of adapting to digital ways of being, rapid developments have brought new technological convergences that are shifting science itself into new fields of disciplinary knowledge. Rather than perceive these subjects as discrete, or in isolation from each other, they might be understood as 'new knowledge ecologies', rapidly emerging in a postdigital landscape where technological ability now shapes science (Peters, Jandrić \& Hayes, 2021a).

In this context, biology as digital information, and digital information as biology, are now dialectically interconnected (Peters, Jandrić \& Hayes, 2021a) which in turn requires new conceptions in policy, and extensions to traditional and contemporary theories.

\section{3}

Airing New Postdigital Policy Discourse

Now that new scientific activities are driven primarily through what can be digitised, data has become a very valuable commodity. This takes us deeply into 'a world where a mining of the psyche takes place within bio-informational capitalist networks that require the surrender of autonomy for a full integration into the circuitry' (Peters, 2019). Ramge (2020) suggests that Artificial Intelligence (AI) abuse is increasing in three main ways in the digital economy: (1) via a monopolisation of data by large Information Technology (IT) companies and Internet platforms, (2) through manipulation of the individual in the commercial space where the interests of companies rather than users are advanced and (3) in the abuse by political actors and regimes through surveillance, incentives and repressive measures. Raising the question: what 
do we actually want the future to resemble? (Ramge, 2020) therefore cuts to the chase on the 'hot air' surrounding inclusivity agendas. There are futures where AI systems can 'relieve us of tedious tasks', or 'improve health and education' or bring about 'sustainable development to increase prosperity for all' and 'strengthen democratic discourse instead of undermining it in the echo chambers of social media' (Ramge, 2020). New postdigital policy discourse is therefore necessary to determine ways to 'achieve a successful synthesis of the analog and the digital', to 'use intelligent machines intelligently'. Ramge argues that 'postdigital citizens workers and consumers' should no longer 'fall for the big tech corporations promises of salvation' (Ramge, 2020). Furthermore, amid recent biodigital innovations, where biology and technology merge, there is now a use of biology to make products which takes us down a potentially new economic and disciplinary trajectory. This is a route where human philosophical goals of inclusivity and equality might be furthered via the principles of bioeconomy, environmental self-renewal and new synthetic enhancements. Such a biologisation of digital processes may reflect a very different kind of political economy (Peters, Jandrić \& Hayes, 2021a, 2021b).

Human habits in a virtual environment may seem different, but such perceptions then have a tendency to mislead approaches towards policy in universities concerning digital change. Rather than rationalise about what digital technology is 'enhancing' or 'driving' in education, more nuanced understandings are required. This means a shift to how we construct policy and write related strategies in $\mathrm{HE}$, if implications for inclusivity and disadvantage are really to be addressed. The overlap and parallels across physical and virtual environments, as well as across space and time, are more aptly observable now in the notion of a postdigital society that all of us inhabit, rather than simply to discuss digital drivers. In taking a postdigital perspective towards policy a continuity is recognised across online and offline experiences, knowledge and cultural theory prior to digital advances, and our anticipated futures.

Interdisciplinary theories about the mutually constitutive relationship of technologies in individual human lives (Mackenzie \& Wajcman, 1999, Braidotti, 2019a) recognise that people shape, and are shaped by, technology and culture. They make postdigital choices, as they connect with old and new media, with predigital artefacts like my airing cupboard of bricks and mortar, with digital systems and postdigital entireties. As Feenberg has commented: 'the postdigital no longer opposes the virtual or cyber world to the world of face-to-face experience. The digital is integrated and imbricated with our everyday actions and interactions' (Feenberg, 2019: 8). A postdigital perspective on inclusivity requires attention to be paid to the technological 'plumbing' of the Internet and of our institutions, to who and what is controlling such infrastructures and to the risks of not connecting people, activities and objects. 
There is a need to review uses of language and effects of datafication. Thus, debate might be aired on what a postdigital inclusivity policy discourse might look like, as universities endeavour to respond.

Rather than refusing to speak to someone in the family who has aired some 'dirty laundry' about me in some manner, I can now 'unfriend' them effortlessly on Facebook, discuss them over Twitter, or avoid their LinkedIn invitation, as well as close my front door in their face. Unlike ignoring their knock on my door though, or their phone calls which are one-to-one encounters, my activities in the virtual airing cupboard have a much wider reach. What links the online and offline 'airing' of opinion is a use of natural language, which of course I have applied in my chosen analogy to airing cupboards. Annika Mann (2018) has pointed out the 'contagious' aspects of language that have long interested theorists concerning how ideas in general spread, but she also notes the intersection between contagion and language. When a biological threat strikes, such as Aids or the Covid-19 pandemic, there is a contagion both from the 'communicable disease and its means of communication' (Mann, 2018). New words and phrases find their way into circulation, alongside the ideas that they are transmitting. It can then almost appear as if our language is mutating rapidly before us, rather like a virus itself. One example can be noticed in the term covidiot which blends together covid and idiot to describe those who don't keep a distance from others to avoid catching and spreading the Covid-19 virus, or who refuse to undertake quarantine, once infected with it.

In terms of government policy, the notion that the fight against the Covid19 virus entails 'following the science' has been a much-used phrase during 2020 and 2021. As vaccines for Covid-19 have been developed, the behaviour of countries with regard to global distribution has been discussed as 'vaccine nationalism' or 'vaccine diplomacy'. Such words and ideas take the form of cultural truths that are moulded and then spread within discourse. They may also get treated as if they are universal representations of reality, where one dominant set of values overrides others.

However, perhaps a little controversially, Frank Van Splunder (2020) argues that languages do not exist anyway. In Language is Politics, he describes languages as constructions. We may speak of natural languages, as opposed to 
computer generated codes perhaps, but even so-called 'natural' languages are in fact artificial constructions too. On this basis, language has a strength in acting rather like a fluid form of mortar to develop and construct our human thinking, but also to apply ideas to objects and commodities. In our consumer culture many goods, services and products are injected with human qualities and acts of thought, labour or feelings (Hayes, 2019a), as demonstrated in the advert on the silo pictured in Figure 2.

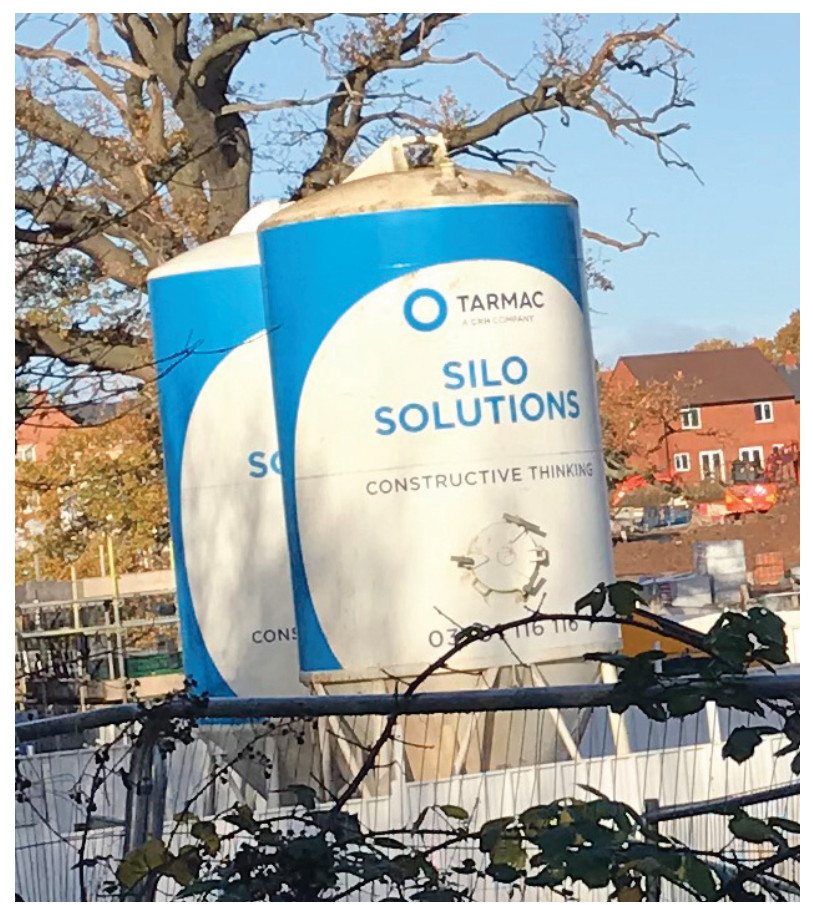

FIGURE 2 A dry mortar silo attributed with its own form of constructive thinking

Yet sometimes something so obviously commercial, as in this photo I took of a dry mortar silo on a local building site, as it professes to be undertaking 'constructive thinking', can (in its own way) contribute to further theory and debate. It might even help us to avoid the silos of theory that can occur in $\mathrm{HE}$, leaving disciplines sitting apart from each other, when they might instead engage in constructive thinking about areas of convergence.

Firstly, languages enacted as discourse can construct one particular world view (when others may exist), even lies can sound as if they may be true. Secondly, languages are used to construct identities. Van Splunder (2020) gives the example of identities of nations, groups or individuals that can be defined by who they are, or against who they believe they are not. Then there is the actual linguistic construction that takes the form of grammar, vocabulary and 
spelling. The order of words and the patterns in which these are placed can manipulate, differentiate and control meanings to serve certain needs and ideologies (Van Splunder, 2020, Hayes, 2019a).

In postdigital society, the close associations between many contributing forces to such 'truths' are recognised. These include technology, culture, biology, language and information, all as causal and inseparable contributors to what is transmitted in discourse. As these and other political and economic forces intermingle with human values and viruses, cultural evolution in postdigital society is driven through 'bioinformationalism', via a 'viral modernity' (Peters, Jandrić \& McLaren, 2020). Therefore, recognising positionality in postdigital contexts helps to indicate too that 'knowledge and voice are always located in time, space and social power. The concept of positionality refers us to the who, where, when and why of speaking, judgement and comprehension' (Barker \& Jane, 2016: 643). On this basis, the virtual airing cupboard of the Internet might also be aptly described as a viral airing cupboard. If a physical airing cupboard is a warm ecosystem where I might be able to grow something, the online airing cupboard may be virtual, but it has a vast potential to germinate, grow and rapidly spread ideas. Whilst such comments about the Internet are hardly new, many more devices now connect online environments with our physical and natural living circumstances. This is never more so than during the lockdown periods aiming to reduce the Covid-19 infection, which saw a huge surge in online activity of all kinds, even if this did not include everyone globally, in terms of access. Furthermore, in a postdigital context (Jandrić, Knox, Besley, Ryberg, Suoranta \& Hayes, 2018) personal positionalities on the most intimate of topics are now shared publicly across multiple platforms and forums. Unlike a whispered secret though, these narratives remain active and independent of the human who first shared them. Each posting, comment or response becomes detached from the location, personal viewpoint and original positionality of the person to whom these words once belonged. Free of context, words and ideas can travel and modify as this data is picked up by others. In this way a 'super-spreader' of misinformation online can appear to resemble a 'superspreader' of an infectious virus. A close association between viral biology on the one hand, and information science on the other, can lead to further analogies between viral 'epidemics and infodemics' (Peters, Jandrić \& McLaren, 2020).

However, despite all kinds of mutation of communications, what gets stated, uploaded, captured or shared still has an originator. A topic communicated can be revealing in content, but it also says something about those who shared 
it (whether they are human or not). As such, positionality theory, where identity is fluid, dynamic and contextual, is one way to examine individual experiences in postdigital society and to discuss implications for assumptions about inclusivity in HE policy.

Positionality is understood as the intimate and ever-changing social, technological and political contexts that intermingle with, create and continue to influence, a person's values, identity and opportunities. This could include impacts on their gender, race, sexuality, class, location, ability, prospects and many other factors, and so identity remains fluid within relations of power. Through examining positionality, a critical analysis of self-understandings becomes possible, via reflexivity. In short, reflexivity provides our individual route towards unpacking our postdigital positionality and considering the positionality of others. Given all that now happens in the virtual airing cupboard, and its interconnection too with everything outside of it, reflexively engaging with our postdigital positionality can help us to retain some sense of agency. As a point of anchor, it can provide a resistance to being objectified as data alone. It enables each of us to subjectively provide our own fluid narratives, as people who are both cultural and technological citizens in postdigital society.

The ways in which a person's identity is also shaped by new cultural, technological and biological influences (depending on their positionality) brings additional challenges for inclusivity agendas. Furthermore, potential bias or discrimination experienced by individuals can now be shaped by multiple combined factors (Morris, 2020a) that remain 'real' across online and offline locations. The virtual airing cupboard of the Internet can seem like a warm familiar environment for me to share my 'dirty laundry', as I sit in my physical (or virtual) room on my laptop choosing what language I will use to comment in an online forum. What I write there is not though simply picked up by a human hand, like the laundry from the hall cupboard. A letter I might once have sent through the post via a post box went to a specific addressee. Data that I share now can be categorised by a computer without my knowledge and according to parameters that I am unaware of. It can be reused, as well as read, re-read, downloaded, edited and forwarded, along with any images I have aired too. The content can be internalised by many other humans and devices, edited and shared again. This carries the constant risk of reactions to any values that I may have expressed virtually: there could be legal implications too. I may find that I have become 'unfriended' or that 'dirty laundry' has been posted online about me too. Strangers may have urged others to cut me off or to appropriate aspects of my identity, in ways I had not anticipated, when I first began to type.

Whilst much of this may sound like familiar territory, a further debate now emerges with the convergence between biology and information that is now 
flowing through the virtual airing cupboard. The scenarios described above take place in a paradigm of 'bioinformationalism', which draws a close association between viral biology on the one hand, and information science on the other, to critically discuss how communications 'mutate' across our political economy (Peters, Jandrić \& McLaren, 2020). A new paradigm, 'biodigitalism', also refers to the mutual interaction and integration of information and biology, but this manipulation of biological systems in computational biology is beginning to fundamentally reconfigure all levels of theory and practice (Peters, Jandrić \& Hayes, 2021a). There are new implications for human agency, if critical reason itself starts to require a biodigital interpretation, rather than the other way around. This could shift for example assumptions concerning cognitive processes and the disciplinary traditions from which these positions have emerged over centuries. With a new constellation of forces shaping the future of what humans might become in postdigital society, we encounter too a new biopolitics of identity which brings philosophies of race, class, gender and intelligence, into new compelling dialogue with genomics and information. (Peters, Jandrić \& Hayes, 2021a). There are many non-human positionalities to notice now and to be conscious of the fluid postdigital boundaries they can also cross.

\section{$7 \quad$ Cancel Culture}

Dubbed as 'cancel culture', this is where an opinion shared by someone online but deemed to be unpopular by someone else, leads to a boycott of them as a person. Whether in the name of social justice or social judgement, the person is 'cancelled' by those who feel unhappy about the views that they aired. Cancel culture is one of many socially constructed nicknames for what humans do to others and has become widely 'aired' across online forums. Others such as 'ghosting' (where a person is dropped without a word by someone whom they believed that they were dating online) or 'zombieing' (where the 'ghoster' gets back in touch) reveal similar trends. Yet the notion that a human opinion aired can simply be switched off, or that they themselves might be 'cancelled' - like the next online shopping order that I place, or the sheets that I choose to overlook at the rear of the cupboard - has implications for a person's positionality. Furthermore, the broader implications of accepting (or otherwise) a person or a particular culture's supposed attitudes, can alter each individual's mental wellbeing, access to others, opportunities, participation and their sense of inclusion. People are placed, and replaced, through power relationships that interplay both online and offline. These pass between different digital systems as well as through humans. 
As a result, there are implications for what, and not only who gets to be 'included' these days, in inclusion policies. This requires an underpinning debate about the stance which is taken by each university and those in it towards algorithmic activity and new biodigital knowledge ecologies that are both individual and collective. Universities cannot meaningfully be concerned with inclusivity between humans in isolation from a widespread digitalisation of life taking place all around us. In postdigital society, what is digital is now also closely intermingled with all other aspects of human life, values and emotion and the expression of these, through language (Jandrić, Knox, Besley, Ryberg, Suoranta \& Hayes, 2018). So, whilst my airing cupboard analogy is a figurative one, it helps to illustrate an interplay across physical and virtual circumstances surrounding humans that postdigital theory encapsulates. It is argued that all technological, cultural and biological changes remain with us, whether or not the machines, theories or the practices themselves are still actively in use. Whatever form virtual airing cupboards may now take, in terms of the many devices and online platforms used to express opinions via the Internet, there are now new implications for the construction of inclusivity policies in education, just as there are new postdigital participants and partnerships to be considered.

\section{$8 \quad$ Inclusivity}

The term 'inclusivity' is now widely adopted in organisations and companies across the globe. In HE policy discourse it is frequently interpreted in terms of fairness and equality of opportunity for all citizens to access education as a basic human right, throughout life. Further emphasis may be placed in university equality, diversity and inclusion policies on respecting all identities and cultures of learners, and on institutions adjusting their core values and plans to support such principles. So far so good, but these values expressed in existing policy discourse tend to be based on interactions between human beings alone. Little seems to be 'included' in $\mathrm{HE}$ inclusion policies on how principles of inclusivity, diversity and human rights are now subject to a complex interplay of data, software and communications, via the role that technological platforms and devices play (or don't play) in individual lives. Yet, 'we live in a digital age where the relations between online and offline can have positive impacts on everything from inequality and belonging to climate change but can also have negative impacts in these domains' (Boellstorff, 2016: 397).

In what has been discussed as a 'knowledge society' (Delanty, 2001), where digital technologies increasingly shape knowledge across multiple forums, 
concerns over fake news in an era of post-truth have gripped global society. An inclusive and empowering approach is to see valid knowledge as that which 'includes an acknowledgement of the knower's specific position in any context, because changing contextual and relational factors are crucial for defining identities and our knowledge in any given situation' (Maher \& Tetreault, 1993). Furthermore, whilst gender, race, class and other aspects of our identities may be perceived by some people as rather fixed in nature, to understand these features of each of us, as markers of relational positions, rather than essential qualities (Alcoff, 1988) enables a clearer understanding of how technologies constantly intermingle with the facets of who each of us are. This is a powerful route too, towards maintaining our own agency in whatever situations we encounter online and offline and in determining what knowledge can be treated as valid.

Throughout 2020 and 2021, the Covid-19 pandemic and related lockdown policies contributed to a dramatic increase in the use of online systems to support learning, health and welfare. Some people were better positioned than others, in terms of their access to digital devices and their skills to interact through these, depending on the levels of existing disadvantage that they faced. A realisation of these disparities has led to wider discussions about digital inclusion and concerns over digital poverty, but much of this focuses around the simple task of supplying laptops to those without them. The complexities in relation to skills, data, ethics, shared or inappropriate learning spaces, disabilities, motivations and many other deeply contextual factors remain unaddressed. Amid these rapid changes, and on the back of huge amounts of work on inclusivity in $\mathrm{HE}$ in recent years, a common assumption remains also that 'the principles of inclusive practice are well established' (Department for Education, 2017). However, this does not explicitly say which 'principles', what forms of 'practice', or by whom these were in fact 'established'. It is necessary therefore to review such suppositions and reconsider both what might constitute inclusivity, and what we can now feasibly include, in our $\mathrm{HE}$ policies for inclusive practice.

\section{Inclusion in Policy Discourse and a Need for Postdigital Dialogue}

It is not my intention in this book to undertake extensive critical linguistic analysis of policy statements like the one above on inclusive practice, as was the case in The Labour of Words in Higher Education (Hayes, 2019a). When I drew attention then, to what I referred to as McPolicy, it was to demonstrate a lack of inclusivity in HE policy texts in themselves, via a sustained pattern of 
omitting direct references to the actual people who enact teaching, research and other related professional activities. I pointed out that, via nominalisation, 'things', such as technologies, strategies or buzz phrases are frequently attributed with having accomplished particular outcomes, instead of attributing those outcomes to the labour that has generally been performed by human beings. This is a more subtle linguistic form of cancel culture, but it is one with profound effects on how 'included' different groups might feel in HE policymaking. I argued too, with reference to George Ritzer's McDonaldisation thesis (Ritzer, 1993, 2018), that: 'strong levels of repetition and standardised statements in HE policy begin to resemble any menu in a global catering chain' and:

A similar logic to marketing a regular cappuccino or a gingerbread latte seems to have been adopted in writing HE strategies regardless of which organisation these may relate to. (Hayes, 2019b)

There is something of an irony then, that in adverts for drinks or cars, human qualities are regularly attributed to consumer products, yet in HE policies, ascribing noticeable credit to people for their labour is curiously absent. As $\mathrm{HE}$ has responded to a world structured to meet the needs of capitalism and global markets, policy discourse has rationally reflected this in a narrow form of reasoning that prioritises productivity and homogenisation for efficiency. Just as Ritzer noticed a 'fast food' model of efficiency, calculability, predictability and control had become repeated across companies and organisations, their policy language has come to mirror this. However, Ritzer also observed that such rationalities can eventually become irrational (Ritzer, 1993, 2018). What has happened in $\mathrm{HE}$ is an irrational separation between two rational policy discourses. On the one hand, the discourse that argues technology is driving change, enhancing learning and employability, tends not to reference human labour in these processes. On the other hand, the policy discourse for social welfare, human rights and inclusivity in $\mathrm{HE}$, tends not to refer to technology. These observations build on a disconnect already observed by Delanty (2001) some twenty years ago. He argued that:

the challenge facing the university today is to link cultural reproduction and technological reproduction. (Delanty, 2001: 157)

Delanty discussed a market-driven capitalism 'shaping the university in the image of technoscience', as disengaged from 'battles of cultural identity' (Delanty, 2001: 157). What is needed instead is for universities to be the location 'where these discourses intersect' (Delanty, 2001: 158). Rather than an exclusive 
intellectual exchange that remains inside the walls of an institution, it needs to be an inclusive, cross-sector debate led by the university:

linking the requirements of industry, technology and market forces with the demands of citizenship. (Delanty, 2001: 158)

Postdigital positionality offers a powerful route towards re-engaging the separate terrains of culture and technology with citizenship in an ongoing, inclusive, 'postdigital dialogue' (Jandrić, Ryberg, Knox, Lacković, Hayes, Suoranta, Smith, Steketee, Peters, McLaren, Ford, Asher, McGregor, Stewart, Williamson \& Gibbons, 2018). This is a community dialogue which universities can and should take a lead on, in collaboration with schools, human rights agencies, charities, legal and technical experts and individuals (UPP Foundation, 2018, Hambleton, 2020, Hayes et al., 2020). This is not least because an innocent sounding term like 'data' now brings acute risks to those most vulnerable in society (The State of Data, 2020: 5). Daily breaches of human rights are clinically discussed as 'data'. However, data becomes a form of shorthand, a proxy for what is frequently intimate human information and activities undertaken by our young children, through to our elderly citizens. This is a reality that leaves the vulnerable unprotected and our children: 'creating a resource that for-profit companies gain from' (The State of Data, 2020: 5). As both a personal and interpersonal dialogue, this is currently an incomplete and pressing societal exchange that, if led by universities, to include schools through from early years and across lifelong learning, would help to more inclusively inform our 'inclusivity frameworks'.

\section{Inclusion in Decisions about Our Data Requires Some 'Re-plumbing'}

Outside of the university, the territories of cultural reproduction and technological reproduction are deeply interconnected across the virtual airing cupboard of the Internet. Not only does the Internet connect 'people in vast numbers' it 'allows inanimate objects' to connect too (Seldon, 2020: 160). Known as the Internet of Things (IoT), this 'facilitates the collection of big data on a scale we are still unable fully to access or exploit, as the sheer volume can mitigate against sifting the quality from the unreliable evidence and forming solid conclusions' (Seldon, 2020: 161). A danger arises though for HE as a sector if it potentially joins the existing 'smart schools', by the creation of 'smart universities'. These are now developing akin to 'smart cities' with institutions 
'working to connect online services which are currently separate' (Seldon, 2020: 161). Yet it is also an uncertain time to be investing heavily in physical educational spaces when the pandemic has propelled so much of our HE activity online. That aside, as inclusive as these virtually linked campus environments may sound, we are failing (metaphorically speaking) to connect some vital plumbing underneath.

Treating such developments as simply technological efficiencies, leaves universities vulnerable. If we do not take time to reconnect old pipes with new digital wires and linguistic communications, so to speak, we will continue to perpetuate inequalities and to exclude citizens from vital knowledge about what their 'data is up to' when it's out on its own. We need to metaphorically undertake the 'plumbing' that enables us to see how cultural reproduction and technological reproduction are intertwined. When these are treated separately, Internet giants and big businesses are free to further inequality reproduction (Ball, 202O). Therefore, to recognise the realities of what data-driven technologies are driving apart between culture and technology, provides insights to act quickly to preserve human rights.

Omitting such concerns from our university inclusivity strategies, via nominalised McPolicy statements, where entities other than humans are said to 'act', displaces people (Hayes, 2019a: 148). In urging readers to observe persistent configurations of McPolicy, I noted, in parallel, some of the ways in which rapid patterns of technological change in wider global society can disempower, as well as empower people. In particular, the data-driven systems, robotics, and unseen algorithmic activities that cannot easily be contested, leave users with little control over their own data, or its utilisation. When things and statements, rather than people, accomplish particular outcomes this leaves all of us acutely vulnerable, with our labours unattributed, and 'things' of all kinds free to act. Later I will demonstrate how even my humble airing cupboard in the hallway might be harbouring its own 'aspirations' to become more connected. If we fail to reflect on an interconnection between technoscience and cultural identity though in our HE policy discourse for inclusivity, then instead of catching up, universities (and the people within and around them) now risk being cancelled.

Related issues have been raised by scholars of Human Data Interaction (HDI) who have called for greater inclusivity for people in decisions concerning their personal data. They argue that each of us needs to understand what is happening to the data that is being gathered about us as individuals (legibility) and to be able to change relevant digital systems. We will then be in accord with our own wishes (agency) and will be able to work with those who are processing our data (negotiability). As such, there is a need for analytics algorithms to 
be more transparent and comprehensible to people and for those systems that process data to give people more capacity to control, inform and correct their data. Support is called for too, to help people re-evaluate their decisions about their data held within commercial systems as their circumstances change (Mortier, Haddadi, Henderson, McAuley \& Crowcroft, 2014).

\section{$11 \quad$ McDonaldisation of a Virus}

This has become ever more pressing during the Covid-19 pandemic, that has through necessity, accelerated the scope of people to work and study from home and dramatically increased the use of computing to teach, learn and research online. This has implications for how HE responds to equality, diversity and inclusion matters under these new circumstances, when this situation is unlikely to reverse significantly into the future. Increased necessity to access the Internet has taken university business wholesale online. Just like many other forms of work currently being conducted from peoples' homes, this leaves scope for viral forms of McDonaldisation (Ritzer, 1993, 2018) of workplaces and workspaces to take hold. Remote methods for controlling the efficiency of employees working in their homes provide new ways to calculate and control productivity. Covid-19 has taken many of us much deeper into the virtual airing cupboard than before, but we don't all arrive there with equal support or capabilities. This wholesale change has not though, placed the Internet business model of aggressive advertising, commercial techniques for transfer of data or concerns over cyber security and anonymous manipulation of user activity inside the university for more scrutiny.

Universities do not control the World Wide Web. This means there is more scope now for students and staff to be tracked, their data to be breached and manipulated, their comments to be trolled or cancelled, their privacy to be violated, alongside any positive developments in terms of increased digital skills, flexibility and wider communication opportunities. As James Ball (2020) has pointed out:

Browsing the internet feels like something safe and private. The intrusion is invisible. (Ball, 2020: 204)

Whilst universities engage mostly with the social and cultural aspects of inclusivity policymaking, the technical ones often go unnoticed. However, the technical aspects are closely interlinked to enormous commercial and government powers and human rights violations via the Internet (Mozilla Manifesto, 
2003). Universities now need to connect their support for inclusivity with raising awareness of people's digital (and postdigital) rights; given that these are now further impacted in numerous ways due to Covid-19 (EFF, 2020). In the UK, consultation has begun on a national data strategy, further demonstrating the strong role that data now plays in anticipated futures (GOV.UK, 2O2Oa). This very sudden situation of shifting so much online due to the pandemic has played out very differently in each individual human context. Guest editors for a special issue of the Journal of Literacy and Technology have entitled this collection: The eLearning Literacy for Suddenly Online (2020). In this 'suddenly online' situation (Wallace, Burton, Chandler \& Darby, 2020) there are also many data-related precarities that can be encountered. Whilst HE regulators and journalists are keen for universities to tell their 'inclusivity stories' supported by selective data, it is necessary for inclusivity frameworks to be cognisant of ethics and human rights in relation to data-driven systems. This is difficult to do though, if inclusivity policy continues to treat cultural issues as separate from technological ones.

Whether observing an absence of references to human labour in policy, or noticing the rise of autonomous machines, algorithms and opaque data agreements, this does not mean that people are not still present in the background, writing policy, programming, coding, making judgements in the design of systems, or deleting each other from social media accounts. That the instruments we use to write with have implications for what we write, has perhaps always been true to some extent. Now, new networks of information, systems, images, video, coding, apps and data are integral to all of our human processes across life. As the need for social distancing has been evident during this pandemic: 'large global companies such as Google, Microsoft, Facebook and international organisations including the Organisation for Economic Co-operation and Development (OECD) and UNESCO, as well as a global education industry of edu-businesses, consultancies, investors and technology providers, are coming together to define how education systems should respond to the crisis' (Selwyn, Macgilchrist \& Williamson, 2020). The data-driven nature of such alliances brings privacy and surveillance concerns, alongside disquiet at the swift adoption of commercial platforms at scale, without significant vetting procedures. Despite aspirations towards addressing inequalities remotely, the profound longer-term implications for systems of public education need to be considered too (Selwyn, Macgilchrist \& Williamson, 2020). This postdigital 
context or fusion of human and digital activity, brings both emancipation and new forms of bias, ethical issues and impact on existing systemic inequalities. How these intimate connections interplay to affect each individual as a global citizen, I argue, has wide-reaching implications for the inclusivity debate in $\mathrm{HE}$, for how we write policy, and for what universities can, or cannot claim to be able to control.

Universities are required to respond to legislation such as the Equality Act (2010) and the Public Sector Equality Duty (2011). This includes the annual publication of information and measurable objectives which focus on the elimination of discrimination, the advancement of equality of opportunity for people from different groups and good relations between them. Under the Equality Act (2010) human characteristics are protected from discrimination through law (Equality and Human Rights Commission, 2019). The recognised 'protected characteristics' include: age, disability, gender reassignment, marriage and civil partnership, pregnancy and maternity, race, religion or belief, sex and sexual orientation. Public sector organisations are expected to meet the needs of people with protected characteristics and encourage them to participate across public life, including education. These important legal obligations can though, become rationally interpreted in policy discourse in ways that simply focus on the compliance of people around certain individual topics. This approach may be efficient in publishing information and objectives, but it overlooks broader interconnections.

In a recent campaign, a review of the Equality Act has the 'aim of amending this landmark anti-discrimination legislation' (The Equality Act Review, 2020). There are calls for new factors to be taken into account, such as homelessness or immigration status, but then there are also questions of which of the most vulnerable should receive a Covid-19 vaccine in terms of priority. Decisions are complex where there is an intersection with existing protected characteristics, and new potential characteristics as these emerge. There are also more hidden forms of bias that have surfaced. These include questions concerning the compliance of data-driven digital systems that may have integral forms of bias (Mortier, Haddadi, Henderson, McAuley, Crowcroft \& Crabtree, 2020) yet are part of decision processes concerning humans. There are bioinformational and biodigital developments too that could fundamentally affect how inclusivity is experienced by individuals in the near future (Peters \& Jandrić, 2019, Peters, 2020a, 2020b). 
How people are positioned in relation to combinations of protected characteristics, access to services and their perceptions of inclusivity are no longer formed through human interactions alone. Devices that generate data change context as they are shared between individuals or other devices, and individuals change context as they move around in space and time (Mortier, Haddadi, Henderson, McAuley, Crowcroft \& Crabtree, 2020: 34). Now that so many communications and other activities are conducted across virtual and physical spaces (together), new cultural interpretations of what is understood by inclusivity are bringing complex arguments to this arena. The role of 'bioinformation' (Peters, Jandrić \& McLaren, 2020) is one of these. The 'biological' information generated about individuals in healthcare, health-related research, screening, or testing services may concern an individual's past or present physical or mental health, future health risks, and even bodily constitution. The personal value of bioinformation has gained much interest, including for example 'the role it could play as a predictive, explanatory, descriptive, or relational tool in an individual's construction of the narrative that constitutes her identity' (Postan, 2016: 148). These are new dimensions to individual positionality and are not necessarily visible, unlike the media stories that bring various perspectives on marginalised groups to our attention, or indeed the social media systems that provide ways for people to share these, include, exclude, discriminate against, or even cancel others. Depending on the positionality of those involved, different forms of discrimination can quickly acquire new angles (and audiences) that do not necessarily help those affected. For example, Mirzaei (2019) cautions against a recent dilution of meaning in relation to the term 'woke', which first arose in the 1940s to symbolise 'awareness of social issues and movement against injustice, inequality, and prejudice'. Woke was 'originally associated with black Americans fighting racism, but has recently been appropriated by other activist groups', even now being 'cynically applied to everything from soft drink to razors' (Mirzaei, 2019).

Ritzer (2018) has pointed to all manner of augmented forms of McDonaldisation that have arisen as digital systems have merged with physical life. His ongoing adaptation from Weber's theory of rationalisation (Weber, 1930) that has taken new forms in our postdigital global culture is helpful in noting the many irrationalities that can occur (Ritzer, Jandrić \& Hayes, 2018). One example is the rational approach we have adopted in the UK to support us in measuring inclusivity and diversity in universities. Based on capturing and benchmarking data against certain indicators (Office for Students, 2018-2022) this may, at the same time, be overlooking hidden forms of bias. These can be running through the data-driven systems themselves that are silently furthering the disadvantage of some people over others (Mortier et al., 2014, Mortier, 
Haddadi, Henderson, McAuley, Crowcroft \& Crabtree, 2020). It is now necessary to question exactly what counts as 'data' in relation to inclusivity. If we are asked to measure any data then we can question, is it static or fluid? As such, who and what we are measuring, via which systems, and whether these have been designed with inclusivity, equality and diversity values at the centre are all important considerations.

\section{Inclusivity Is Not a Static Concept That Institutions Can Control}

These and many other complexities arising from human technological relations mean that inclusivity, like identity, is not a static concept that might be applied in relation to humans alone. However, if university policymaking begins only from the concept of human-to-human interactions, where 'the principles of inclusive practice are well established', then it is hardly surprising to find institutions making claims like these:

The Strategy aims to deliver measurable equality and inclusion outcomes for both students and staff. (University of Greenwich, 2019-2022)

The University will proactively mainstream equality and diversity into all areas of decision making, leadership development, committee representation and policy review. (Keele University, 2018-2022)

The statements above fit with what is required under the legal Acts already mentioned, but following the patterns of McPolicy that I have outlined above, the linguistic structures also claim that 'the strategy' or 'the university' (rather than human beings) 'aim to deliver' or will 'proactively mainstream' equality, diversity and inclusion. The 'measurable equality and inclusion outcomes' in Equality, Diversity and Inclusion Strategies like these are worth reflecting on too. Can 'equality and inclusion outcomes for both students and staff' be 'delivered' at all when there are so many unseen aspects at play? How are such outcomes to be defined for diverse individual students and staff, with or without declared, protected characteristics? Who measures these, in what ways and what else might be intersecting with what people perceive as their identity, or indeed define as inclusivity? Such statements also presuppose that equality and inclusion outcomes (and related data) remain fixed for these to be measurable or mainstreamed. Taking on very broad inclusivity agendas to suggest that they might be addressed in this rational way, raises questions concerning exactly what universities can, or cannot, meaningfully control. They can 
provide information, but whether university web pages providing advice on topics like 'how to be a white ally' (University of York, 2020) contributes to sustained systemic change in relation to discrimination, is open to debate. Many institutions are responding in similar ways to each other, but there are also questions of whether imposing a uniformity of institutional response to agendas of race, gender or disability is in fact the same as being inclusive.

\section{5}

\section{New Ethics and Ownership Questions}

There are now though further urgent ethical questions to bring to the ones already outlined above. These include interrogation of a proliferation of new technological platforms and advances in the ways to gather data on students (Williamson, 2017). Scientific efforts to aid the better understanding of human learning and achievement have broadened across many academic disciplines, as new digital technologies have enabled re-examination of existing educational issues (Kuhl, Lim, Guerriero \& Van Damme, 2019). Ben Williamson has drawn attention to movements by education data scientists and learning engineers towards making students themselves 'machine readable' by gathering data on their living bodies. He argues that artificial intelligence (AI) systems are being combined with learning science in 'digital laboratories' where 'ownership over data, and power and authority over educational knowledge production, are being redistributed'. This is leading to 'highly contested understandings of biological learning bodies' and 'creating new data objects as ways of conceptualizing learning and educational outcomes' (Williamson, 2020c).

In a recent report for UNESCO, the challenges of 'datafication' (MayerSchönberger \& Cukier, 2014a, 2014b) are also balanced against 'a world of possibilities in terms of individualising learning and education governance' in the developing world (Pedro, Subosa, Rivas \& Valverde, 2019). Such broader developments, challenges and possibilities also impact on inclusivity policies as universities adopt these commercial systems. The ethics of these need to be considered also alongside the personal choices made by people using their own devices. Whilst one mobile phone user may wish to have dynamic content aggregated for them based on their personal activities and movements, their commute to work, or their patterns of consumption, others may not. In HE, learning analytics welcomed by one student, may be intrusive for others.

Applications of tangible human data and other rapid digital developments have implications for how universities continue to construct equality, diversity and inclusion policies and frameworks. There are consequences too for how institutions seek to eliminate attainment gaps, how they discuss groups 
who they hope to target, to improve these figures and the actions that they might take. Yet in a recent report addressing this topic (UUK and NUS, 2019), there was no mention throughout of the role that such technological developments now play. Nor was digital technology referred to in relation to equality and diversity objectives in the strategy for the Office for Students (Office for Students, 2018-2022). If these changes are overlooked, policies will remain focused on ingrained inequalities, bias and disadvantage at only human-tohuman levels. It is now necessary to also consider and explore the complex and dialectical human-technological relations that are currently missing from university inclusivity frameworks. How these intersect with each individual's levels of digital skills and their various forms of disadvantage, can lead to profound marginalisation rather than empowerment to enter and succeed, in education and the workplace. Whilst there are many angles that might be taken, my aim in this book is to gather together a collection of current arguments from recent literature with implications for re-establishing how inclusivity policy is perceived in HE. This is intended to aid the discussion about how to reform current styles of writing $\mathrm{HE}$ policy documents that, presently, not only isolate humans from technology, but also isolate many interconnected issues from each other. I will draw sources together through a fusion of two academic theories that are not currently brought into active dialogue with each other. In so doing, I will introduce the concept: 'postdigital positionality', as a potentially productive way of furthering this debate. 